\title{
Düşük Sosyo-Ekonomik Düzeyli Ailelerde Kronik Otitis Media ile İlişkili Risk Faktörlerinin Değerlendirilmesi
}

\author{
Evaluation of Chronic Otitis Media-Related Risk Factors in Low Social-Economic Levels
}

\author{
Yavuz GÜLER ${ }^{1}$, Rukiye GÜLER ${ }^{2}$, Alper ŞEN $^{3}$, Muhammet Fatih TOPUZ $^{4 *}$, Kadir ÖZDAMAR ${ }^{3}$, Esra Aycan ÜSTYOL $^{5}$ \\ ${ }^{1}$ Ballkllgöl Devlet Hastanesi Kulak Burun Boğaz Hastalkkları, Şanlıurfa; $\quad{ }^{2}$ Şanlıurfa Eğitim ve Arașttrma Hastanesi Kulak Burun Boğaz Hastallklarl, \\ Sanlurfa; ${ }^{3}$ Harran Üniversitesi Tip Fakültesi Kulak Burun Boğaz Hastallklarl AD, Şanlurfa; ${ }^{4}$ Kütahya Sağllk Bilimleri Üniversitesi Tip Fakültesi \\ Evliya Çelebi Eğitim ve Araştırma Hastanesi Kulak Burun Boğaz Hastalıkları AD, Kütahya; ${ }^{5}$ Ballklıgöl Devlet Hastanesi Biyokimya Bölümü, Şanlıurfa
}

\section{$\ddot{O Z Z}$}

Amaç: Bu çalışmanın amacı düşük sosyoekonomik statüdeki popülasyonda kronik otitis media (KOM) ile ilişkili olduğu düşünülen bazı değiştirilebilir risk faktörlerinin rolünü incelemek ve bu konuda geliştirilebilecek sağlık politikalarına katkıda bulunmaktır.

Gereç ve Yöntemler: 1 Ekim 2017 - 1 Mayıs 2018 tarihleri arasında Balıklıgöl Devlet Hastanesi Kulak Burun Boğaz polikliniklerine başvuran ve gönüllü olan düşük sosyo-ekonomik düzeye sahip 759 hasta değerlendirildi. Tüm hastaların öyküsü alınarak muayenesi yapıldı. Perforasyonlu KOM tanısı otoskopik muayenede kulak zarında 3 aydan uzun süreli, iyileşmeyen perforasyon bulunması ile konuldu. Hastalar en az bir kulakta perforasyonlu KOM'u olup olmamasına göre iki gruba ayrıldı. Tüm hastalar yaş, cinsiyet, ebeveynlerin eğitim durumu ve meslekleri, yaşadıkları evin durumu, evde yaşayan birey sayısı, ekonomik gelirleri, anne sütü alım süreleri, mama kullanımı, biberonla beslenme ve pasif sigara içiciliği öyküleri açısından sorgulandı.

Bulgular: Calıșmamıza dahil edilen 759 hastanın $221(\% 29,1)$ 'ine perforasyonlu KOM tanısı konuldu. Gruplar karșılaștırıldığında KOM $(+)$ hastalarda kadın cinsiyet oranı, pasif sigara maruziyeti ve biberonla beslenme; KOM (-) hastalara göre istatistiksel olarak anlamlı izlendi $(\mathrm{p}=0,035, \mathrm{p}<0,001$ ve $\mathrm{p}=0,048)$. Anne okur-yazarlık oranı KOM $(+)$ hastalarda, KOM (-) hastalara göre anlamlı bir şekilde daha az idi ( $\mathrm{p}=0,041)$. Anne sütü alım süresi 12 aydan az olanlarda perforasyonlu KOM istatistiksel olarak daha fazla görüldü $(\mathrm{p}=0,013)$.

Sonuç: Bebeklik dönemi pasif sigara maruziyeti, biberonla beslenme, kız cinsiyet ve annenin okur-yazar olmaması perforasyonlu KOM riskini arttırmaktadır. En az 12 ay anne sütü kullanımı KOM'a karşı koruyucu etkiye sahiptir. KOM gibi toplumda sık görülen hastalıkların toplumsal dağılımı sosyo-ekonomik seviyeye göre değişmektedir. Toplumun sosyo-ekonomik seviyesi yükseltilerek bu tür hastalıkların prevelansında düşme sağlanabilir.

Anahtar kelimeler: Sosyoekonomik düzey; kronik otitis media; bebek maması; edilgen sigara içimi; biberonla beslenme.

\begin{abstract}
Aim: To examine the role of some changeable risk factors thought to be associated with chronic otitis media (COM) in the low socioeconomic status population and to contribute to the health policies that can be developed in this respect.

Material and Methods: Between 1 October 2017 and 1 May 2018, 759 patients with low socio-economic status were evaluated in Balıklıgöl State Hospital Otorhinolaryngology outpatient clinics. The anamnesis of the patients was obtained and otoscopic examination was done. Patients with perforated COM diagnosed with otoscopic examination were found to have perforation on the eardrum at least 3month. Patients were divided into two groups according to whether they were perforated COM with at least one ear. All patients were interviewed in terms of age, gender, educational conditions and ages of the parents, the household conditions, the number of individuals living in the household, economic incomes, duration of breastfeeding, food use, bottle feeding and passive smokers.

Results: 221 (29.1\%) of 759 patients included in our study were diagnosed with perforated COM. When the two groups were compared; In COM (+), female sex ratio, passive smoking exposure and feeding with bottle were statistically significant according to COM (-) $(\mathrm{p}=0.035, \mathrm{p}<0.001$ and $\mathrm{p}=0.048)$. Maternal literacy was statistically significantly lower in COM $(+)$ than in COM $(-)(\mathrm{p}=0.041)$. Perforated COM was statistically more frequent between $0-12$ months of breastfeeding $(\mathrm{p}=0.013)$.

Conclusion: Passive smoking exposure during infancy, bottle feeding, female sex, and maternal illiteracy increase the risk of perforated COM. Breastfeeding for at least 12 months has a protective effect against COM. The social distribution of common diseases in society such as COM varies according to socio-economic level. By increasing the socio-economic level of society, the prevalence of such diseases can be reduced.

Keywords: Socio-economic status; chronic otitis media; infant formula; passive smoking; bottle feeding.
\end{abstract}

Sorumlu Yazar / Corresponding Author: Muhammet Fatih TOPUZ, drfatihtopuz@yahoo.com

Geliş Tarihi/Received: 06.06.2018 Kabul Tarihi/Accepted: 05.10.2018 


\section{GíRiş}

Sağlı̆̆ı anlama ve değerlendirmede sosyal çevrenin etkilerini değerlendiren biyopsikososyal yaklaşımın son y1llarda tıbbi alanda önemi giderek artmaktadır. Sosyal çevreyi ve buna bağlı etmenleri değerlendirmede sosyoekonomik seviyeden faydalanılmaktadır. İnsanları ailesi ve sosyal çevresi ile bir bütün olarak değerlendiren biyopsikososyal yaklaşımda hastalıkların oluşumu tek bir etkene bağlanmaz (1).

Kronik otitis media (KOM) gibi etiyopatogenezisi multifaktöryel olan ve çevresel faktörlerden oldukça fazla etkilenen hastalıkların toplumun sosyoekonomik seviyesine bağlı sıklı̆̆ değişkenlik göstermektedir (2,3). Yapılan bir çalışmada Alaska yerlilerinde, Amerikan yerlilerinde ve Eskimolarda toplumun geri kalanına göre daha sık görülmüştür (4).

Orta kulak mukozasının 3 aydan daha uzun süreli iyileşmeyen inflamasyonu olarak bilinen KOM; kulak zarında perforasyon olmadan orta kulakta sıvı birikimi ile seyreden kronik effüzyonlu otitis media ve kulak zarında perforasyon ile seyreden perforasyonlu KOM gibi çeşitli formlarda karşımıza çıkmaktadır. Son zamanlarda perforasyonlu KOM ile ilgili yapılan çalışmalar daha çok hastalığın cerrahi tedavisine odaklanıldığını göstermektedir. Hastaların cerrahiye hazırlanma süreçleri ve bu sürede aldıkları medikal tedaviler, cerrahi uygulamalar ve postoperatif dönemdeki kontrolleri iş gücü ve ekonomik olarak kayıplara yol açmaktadır. Ayrıca cerrahinin çoğunlukla genel anestezi altında yapılması nedeniyle anesteziye bağlı komplikasyonlarda görülebilmektedir.

$\mathrm{Bu}$ çalışmada düşük sosyo-ekonomik statüye sahip popülasyonda perforasyonlu KOM prevalansının azaltılmasında etkili olabilecek biyopsikososyal yaklaşımın temelini oluşturan eğitim düzeyi, anne sütü alım süresi, mama kullanımı, biberonla beslenme öyküsü ve pasif sigara maruziyeti gibi bazı değiştirilebilir çevresel etkenlerin KOM gelişimindeki rolünü ortaya koymak ve hastalığa karşı geliştirilebilecek koruyucu hekimlik uygulamalarına katkıda bulunmak amaçlanmıştır.

\section{GEREÇ VE YÖNTEMLER}

Bu çalışmada 1 Ekim 2017 - 1 Mayıs 2018 tarihleri arasında çoğunlukla düşük sosyo-ekonomik düzeyli ailelerin yaşadığı bir bölgeye hizmet veren ikinci basamak bir hastanenin Kulak Burun Boğaz (KBB) Polikliniği'ne başvuran gönüllü hastalar prospektif olarak değerlendirilmeye alındı. Çalışma grubuna alınan hastalar randomize olarak seçildi. Harran Üniversitesi Tıp Fakültesi Etik Kurulundan 07.12.2017 tarih ve 12 sayılı kararı ile etik kurul onayı alındıktan sonra aydınlatılmış rıza onamı alınan 759 hasta çalışmaya dahil edildi. Çocukluk dönemi en fazla 2 katlı ve soba ile 1sitılan evlerde geçen ve ekonomik geliri asgari ücret ve altı olan, çocukluk döneminde aynı evde 6 ve üzeri birey yaşayan hastalar düşük sosyo-ekonomik düzeyli aile bireyleri olarak kabul edildi ve çalışmaya dahil edildi. Tüm hastalara yaş, cinsiyet, çocukluk çağı ekonomik gelirleri, çocukluk çağının geçtiği evin özellikleri ve kışları 1sınma yöntemi, evde yaşayan birey sayısı, ebeveynlerin eğitim durumu ve meslekleri, anne sütü alım süreleri, bebeklik dönemi pasif sigara maruziyeti, biberonla beslenme ve mama kullanım öyküleri soruldu. Bu sorulardan en az birine yanıt veremeyen hastalar, annesinin eğitim durumu ortaokul ve üstü olan hastalar çalışmaya dahil edilmedi. 9 yaşından küçük çocuklar çalışma dışı bırakıldı.

Tüm hastaların detaylı anamnezleri alındıktan sonra ayrıntılı KBB fizik muayeneleri yapıldı. Perforasyonlu KOM tanısı otoskopik ve otomikroskopik kulak muayenesinde en az bir kulak zarında perforasyonun görülmesi ile konuldu. Yeni tanı almış hastalar 3 aylık takibe alındı ve 3 ay sonunda kulak zarında perforasyonun varlığ ile perforasyonlu KOM tanısı netleştirildi. Travmaya bağlı gelişen kulak zarı perforasyonları çalışma dışı bırakıldı. Hastalar kulak zarında perforasyon varlığına göre perforasyonlu KOM olan hastalar $(\mathrm{KOM}(+))$ ve KOM hastalığ bulunmayan hastalar (KOM (-)) olmak üzere iki gruba ayrıldı. Daha sonra iki grup arasında pasif sigara maruziyeti, biberon ve mama kullanma öyküsü yönünden karşılaştırıldı. Ayrıca anne sütü ile beslenme süresine göre; $<6$ ay anne sütü ile beslenmiş, 6 12 ay anne sütü ile beslenmiş, 12-18 ay anne sütü ile beslenmiş ve 18 aydan daha uzun süreli anne sütü ile beslenmiş olarak gruplandırıldı ve istatistiksel olarak KOM (+) ile KOM (-) grupları karşılaştırıldı. Ek olarak KOM (+) ve KOM (-) grupları, annenin eğitim durumuna göre okuryazar olanlar ve okuryazar olmayanlar şeklinde istatistiksel olarak karşılaştırıldı.

\section{İstatistiksel Analiz}

Nicel değişkenin normal dağılım gösterip göstermediği Kolmogorov-Smirnov testi ile incelendi. Normal dağılım gösteren yaş değerlerinin analizi için Student-t test kullanıldı. Grupların cinsiyet dağılımları Pearson Ki-kare testi kullanılarak, kategorik verilerdeki farklılık ise Fisher'in kesin testi kullanılarak değerlendirildi. Sonuçlar; yaş için ortalama \pm standart sapma, cinsiyet dağılımında ve kategorik değişkenlerde ise sayı ve yüzde olarak ifade edildi. İstatistik analizlerin tümü için SPSS v.21.0 (IBM, NY, US) programı kullanıldı ve p değerinin $\leq 0.05$ olması istatistiksel olarak anlamlı kabul edildi.

\section{BULGULAR}

Çalışmamıza dahil edilen 759 hastanın demografik bulguları Tablo 1'de özetlendi. Çalışmamıza katılan hastaların 221 $(\% 29,1)$ tanesine en az bir kulakta perforasyonlu KOM tanıs1 konuldu. Tüm grupta yaş ortalaması $27,4 \pm 13,0$ olup, KOM (+) ve KOM (-) hastaların yaş ortalamaları sırası ile $24,9 \pm 11,5$ yıl (9$68)$ ve $28,3 \pm 13,4$ yll (9-69) idi ( $\mathrm{p}=0,001)$. KOM (+) ve KOM (-) hastalarda kadın cinsiyet oranı sirası ile $\% 64,3(\mathrm{n}=142)$ ve $\% 55,9$ $(\mathrm{n}=301)$ idi. KOM $(+)$ hastalarda kadın cinsiyet istatistiksel olarak anlamlı bir şekilde daha fazla idi ( $\mathrm{p}=0,035$; Tablo 1).

Anne sütü alım süreleri KOM (+) hastalarda; $<6$ ay \%29 (n=64), $6-12$ ay $\% 32,6(n=72), 12-18$ ay $\% 60,2(n=133)$ ve $>18$ ay $\% 74,7$ $(\mathrm{n}=165)$ iken KOM $(-)$ hastalarda; $<6$ ay $\% 15,6(\mathrm{n}=84), 6-12$ ay $\% 23,8(\mathrm{n}=128), 12-18$ ay $\% 60,2(\mathrm{n}=324)$ ve $>18$ ay $\% 73,2$ $(n=394)$ idi (Tablo 2). $<6$ ay ve 6-12 ay anne sütü kullanım oranı KOM (+) hastalarda KOM (-) hastalara göre istatistiksel olarak anlamlı bir şekilde fazla idi ( $<<0,001 ; \mathrm{p}=0,013$; Tablo 2$)$.

KOM (+) ve KOM (-) hastalarda okuryazar olmayan anne oranı siras1 ile \%84,6 $(n=187)$ ve \%78,1 $(n=420)$ idi (Tablo 2$)$. KOM $(+)$ hastalarda okuryazar olmama oranı KOM (-) hastalara göre istatistiksel olarak anlamlı bir şekilde daha fazla idi $(\mathrm{p}=0,041$; Tablo 2).

Biberon kullanımı KOM (+) ve KOM (-) hastalarda sırası ile $\% 52,5(\mathrm{n}=116)$ ve $\% 44,6(\mathrm{n}=240)$ idi. Biberon kullanım oranı KOM (+) hastalarda KOM (-) hastalara göre istatistiksel olarak daha fazla bulundu ( $\mathrm{p}=0,048$; Tablo 2 ).

Bebeklik çağı pasif sigara maruziyeti $\mathrm{KOM}(+)$ ve KOM (-) hastalarda sirasi ile $\% 54,3(n=120)$ ve $\% 33,3(n=179)$ idi. KOM $(+)$ hastalarda, KOM (-) hastalara göre pasif sigara maruziyeti istatistiksel olarak anlamlı bir şekilde daha fazla idi $(\mathrm{p}<0,001$; Tablo 2).

Mama kullanımı KOM (+) ve KOM (-) hastalarda sırası ile \%33,5 (n=74) ve \%40 (n=215) idi. Mama kullanımı yönünden gruplar arası anlamlı bir fark yoktu ( $\mathrm{p}=0,095$; Tablo 2$)$.

Tablo 1. Demografik özellikler

\begin{tabular}{ccccc}
\hline & $\begin{array}{c}\text { KOM (+) } \\
(\mathbf{n = 2 2 1})\end{array}$ & $\begin{array}{c}\text { KOM (-) } \\
(\mathbf{n = 5 3 8 )}\end{array}$ & $\mathbf{p}$ & $\begin{array}{c}\text { Toplam } \\
(\mathbf{n}=\mathbf{7 5 9})\end{array}$ \\
\hline Yaş grupları & & & & \\
$10-19$ & $84(38,0)$ & $148(27,5)$ & & $232(30,6)$ \\
$20-29$ & $64(29,0)$ & $146(27,1)$ & & $210(27,7)$ \\
$30-39$ & $48(21,7)$ & $98(18,2)$ & & $146(19,2)$ \\
$40-49$ & $16(7,2)$ & $38(7,1)$ & & $54(7,1)$ \\
$50-59$ & $8(3,6)$ & $90(16,7)$ & & $98(12,9)$ \\
$>60$ & $1(0,5)$ & $18(3,3)$ & & $19(2,5)$ \\
\hline Cinsiyet & & & & \\
Kadın & $142(64,3)$ & $301(55,9)$ & $\mathbf{0 , 0 3 5}$ & $443(58,4)$ \\
Erkek & $79(35,7)$ & $237(44,1)$ & & $316(41,6)$ \\
\hline KOM: Kronik Otitis Media & & &
\end{tabular}


Tablo 2. Çalışma gruplarının özelliklerinin karşılaştırılması

\begin{tabular}{|c|c|c|c|c|}
\hline & $\begin{array}{c}\operatorname{KOM}(+) \\
(n=221)\end{array}$ & $\begin{array}{c}\text { KOM (-) } \\
(n=538)\end{array}$ & $\mathbf{p}$ & $\begin{array}{l}\text { Toplam } \\
(n=759)\end{array}$ \\
\hline $\begin{array}{l}\text { Annesi } \\
\text { Okuryazar } \\
\text { olmayanlar }\end{array}$ & $187(84,6)$ & $420(78,1)$ & 0,041 & $607(80,0)$ \\
\hline $\begin{array}{l}\text { Biberon } \\
\text { Kullanımı }\end{array}$ & $116(52,5)$ & $240(44,6)$ & 0,048 & $356(46,9)$ \\
\hline $\begin{array}{l}\text { Mama } \\
\text { Kullanımı }\end{array}$ & $74(33,5)$ & $215(40,0)$ & 0,095 & $289(38,1)$ \\
\hline $\begin{array}{l}\text { Pasif Sigara } \\
\text { Maruziyeti }\end{array}$ & $120(54,3)$ & $179(33,3)$ & $<0,001$ & $299(39,4)$ \\
\hline \multirow{4}{*}{ 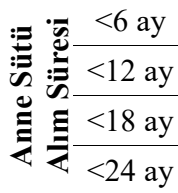 } & $64(29,0)$ & $84(15,6)$ & $<0,001$ & $148(19,5)$ \\
\hline & $72(32,6)$ & $128(23,8)$ & 0,013 & $200(26,4)$ \\
\hline & $133(60,2)$ & $324(60,2)$ & 0,991 & $457(60,2)$ \\
\hline & $165(74,7)$ & $394(73,2)$ & 0,685 & $559(73,6)$ \\
\hline
\end{tabular}

KOM: Kronik Otitis Media

\section{TARTIŞMA}

Sosyoekonomik seviyenin birbirinden farklı olduğu iki kliniğin hastaları arasında yapılan bir çalışmada kronik hastalık görülme sıklıkları arasında farklılıklar tespit edilmiştir (5). Bireyin içinde bulunduğu toplumun sosyo-ekonomik seviyesi ne kadar yüksekse sağlıkla ilgili algısı ve sağlık düzeyi de o oranda yüksektir.

KOM'un daha çok düşük sosyo-ekonomik düzeyli toplumlarda görüldüğü birçok yayında belirtilmiş ve buna neden olarak; popülasyonun hastalığın önemine varamaması, beslenme problemleri, sağlık hizmetlerine ulaşmada güçlük çekmeleri gibi faktörler sayılmıştır (6). Yine sosyo-ekonomik seviye hastahekim arasındaki ilişkiyi etkileyen önemli bir faktördür. Yapılan çalışmalarda sosyo-ekonomik seviyesi düşük olan hastaların yüksek olanlara kıyasla hekim - hasta ilişkisinde daha kötü olduğu ve hastaların daha kötü anamnez verdikleri gösterilmiştir $(7,8)$. Buna bağlı olarak KOM'a ait risk faktörlerinin düşük sosyo-ekonomik düzeyli bireylerde araştırılmasının daha doğru olacağ 1 düşünülebilir. Bu nedenle çalışmamıza tek katlı ve soba ile 1 sıtılan ve en az 6 bireyin yaşadığı evde büyüyen, gelir düzeyi asgari ücret ve altı olan, ebeveyn eğitim düzeyi en fazla ilkokul mezunu olan düşük sosyo-ekonomik statüye sahip gönüllü hastalar dahil edilmiştir.

Çalışmamızda KOM (+) hastalarla KOM (-) hastaların yaş ortalamaları karşılaştırıldığında $(24,9 \pm 11,5$ y1l ve $28,3 \pm 13,4$ y1l $)$ istatistiksel olarak anlamlı bir farklılık bulunmuştur $(\mathrm{p}=0,001)$. $\mathrm{Bu}$ anlamlılığın nedeni olarak KOM (+) hastaların KOM (-) hastalara göre daha genç olması düşünülmüştür. Özellikle KOM (+) hastalarda 10-19 yaş aralığındaki hasta sayısının KOM (-) hastalara göre oransal olarak fazla olmasının etkili olduğu düşünülmektedir. Wahid ve ark. yaptıkları çalışma da bizim bulgularımızı destekler niteliktedir (9). Bu çalıșmada bu yaş grubundaki hastalarda KOM'a bağlı komplikasyonların görülme sıklığındaki artışın nedeni olarak olgunlaşmamış bağışıklık sistemi ve kendi öz bakımlarını gerektiği gibi yapamamaları gösterilmiştir (9).

Çalışmamızda perforasyonlu KOM'un kız cinsiyette istatistiksel olarak daha fazla olduğu görülmüştür. Buna neden olarak çalışmanın yapıldığı bölgede düşük sosyo-ekonomik düzeyli ailelerde erkek çocuğun daha fazla önem görmesi düşünülebilir. Ancak literatüre bakıldığında birçok yayında sosyo-ekonomik düzey ayrımı yapılmaksızın kız cinsiyette KOM'un daha fazla görüldüğü belirtilmiştir (3).

Düşük sosyo-ekonomik düzeyli toplumlarda ev içerisinde sigara içilmesine bağlı pasif sigara maruziyeti de daha sık görülmektedir (10). Nitekim çalışmamızda pasif sigara maruziyeti \%39,4 olarak çok yüksek bulunmuştur. Zhang Y ve ark. 2014 yılında yaptıkları meta-analiz çalışmasında toplam
2971 çalışma incelemişler ve pasif sigara içiciliğinin KOM riskini istatistiksel olarak anlamlı bir şekilde arttırdığını bildirmişlerdir (10). Yine Koch A ve ark. 0-4 yaş aras 1465 kronik süpüratif otitis medialı çocuk üzerinde yaptıkları bir çalışmada sadece pasif sigara maruziyetinin azaltılması ile KOM sıklığının azaltılabileceğini bildirmişlerdir (11). Çalışmamızda da literatüre benzer şekilde pasif sigara maruziyetinin KOM görülme sıklığını istatistiksel olarak anlamlı şekilde artırdığ

Anne sütü bebeğin sağlıklı büyümesi ve gelişmesi açısından önemli bir yere sahiptir. Anne sütünün içerdiği koruyucu İmmünglobulinlerin çocuğu erken dönemdeki enfeksiyonlardan koruduğu bilinmektedir. Literatürde anne sütü kullanımının KOM üzerinde etkisi yönünde net sonuçlar bulunmamaktadır. Kim CS ve ark. yaptıkları bir çalışmada anne sütünün KOM etyolojisinde çok az etkiye sahip olduğunu belirtmişlerdir (12). Bununla birlikte Pedersen CB ve ark. yaşları 3-8 arası değişen 148 çocuk üzerinde yaptıkları bir çalışmada ilk olarak anne sütü alımının ve sonraki dönemlerde bol miktarda süt içmenin otitis media görülme sıklığını azaltmada etkili olduğunu bildirmişlerdir (13). Çalışmamızda ise anne sütünün KOM'a karş1 koruyucu etkiye sahip olduğu görülmüştür. Ancak bu protektif etkinin görülebilmesi için kritik anne sütü alım süresi 12 ay olarak bulunmuştur.

Bebeklik dönemi beslenme biçimi anne sütü sonrasında bağışıklık sisteminin gelişmesinde önemli rol oynamaktadır. Bu dönemde formula mamalar ile beslenmenin KOM gelişimindeki rolü tartışmalıdır. Bu konuda bebeklik dönemi ilk 6 ayda herhangi bir formül mama kullanımını artmış otitis media insidansıyla anlamlı şekilde ilişkili bulan çalışmalar da mevcuttur (14). Ancak çalışmamızda mama kullanımı ile KOM arasında istatistiksel olarak anlamlı bir ilişki bulunamamıştır.

Birçok çalışmada biberon kullanımının otitis media riskini arttırdığı bildirilmiştir (6). Çalışmamızda da literatürle uyumlu olarak biberon kullanımının perforasyonlu KOM riskini istatistiksel olarak anlamlı şekilde artırdığ 1 bulunmuştur.

Literatürde annenin eğitim durumu düştükçe çocuklarda KOM riskinin arttığını gösteren çeşitli çalışmalar vardır. Al Humaid I ve ark. 2014 yılında yaşları 6-12 arasında değişen 1448 çocuk üzerinde yaptıkları çalışmada annenin eğitim düzeyinin ortaokul düzeyinden daha az olmasının otitis media riskini arttırdığını bildirmişlerdir (15).

Çalışmamıza dahil edilen tüm gönüllülerin anne eğitim düzeyi maksimum ilkokul mezunu idi. Bu nedenle anneler okur yazar olup olmamasına göre sınıflandırıldı. Annenin sadece okur-yazar olmaması bile KOM riskini istatistiksel olarak arttıran bir faktör olarak bulunmuştur.

Sonuç olarak düşük sosyo-ekonomik popülasyonda pasif sigara maruziyeti, bebeklik döneminde biberonla beslenme ve annenin okur-yazar olmaması perforasyonlu KOM riskini arttıran ve değiştirilebilir faktörlerden bazılarıdır. Mama kullanımı ile perforasyonlu KOM arasında istatistiksel olarak anlamlı bir ilişki bulunamamıştır. Ayrıca çalışmamızda anne sütünün KOM'a karşı koruyucu olduğu bulunmuştur. Ancak bu protektif etkinin görülebilmesi için en az 12 ay anne sütü kullanmak gerekmektedir.

\section{SONUÇ}

Toplumların tanımlanması ve analiz edilmesinde sosyal, demografik, kültürel ve ekonomik parametreler önemli rol oynamaktadır. Sosyal ve ekonomik ölçütlerin harmanlanması neticesinde oluşan ve başta medeni durum, çalışma durumu, gelir, eğitim, barınma, beslenme gibi temel parametreler sosyoekonomik seviyeyi belirlemektedir. KOM gibi toplumda sik görülen hastalıklarında toplumsal dağılımını sosyo-ekonomik seviyeye göre değiştirmektedir. Düşük sosyo-ekonomik düzeyli ailelerde, anne sütünün en az 12 ay verilmesinin özendirilmesi, ev içerisinde sigara içiminin önlenmesi, okur-yazar olmayan annelere bu yönde eğitimler verilmesi, biberon yerine kaşıla beslenme yönünde eğitim çalışmaları gibi politikaların geliştirilmesi ile KOM sıklığının azaltılması mümkün olabilir. 


\section{KAYNAKLAR}

1. Ak M. Akademik Bir Disiplin Olarak Aile Hekimliği. İnönü Üniversitesi Tıp Fakültesi Dergisi 2010;17(4):403-5.

2. Shaheen MM, Nahar S. Comparison of chronic suppurative otitis media in rural and urban primary school children in Bangladesh. J Laryngol Otol. 2014;128(6):499-503.

3. Lasisi AO, Olaniyan FA, Muibi SA, Azeez IA, Abdulwasiu $\mathrm{KG}$, Lasisi TJ, et al. Clinical and demographic risk factors associated with chronic suppurative otitis media. Int J Pediatr Otorhinolaryngol. 2007;71(10):1549-54

4. Mills RP. Management of chronic otitis media. In: Booth BJ, editor. Scott-Brown's Otolaryngology. 6th ed. Vol 3. Oxford: Butterworth-Heinemann; 1997. p.1-11.

5. Shevchenko M, Davitkov A, Kikerkovska K, Damcevska J. http://woncaeurope.org [Internet]. Influence of socioeconomic status on incidents of diseases in two different municipalities in Skopje. Slovenia: The World Organization of Family Doctors; 2015 March 29 [Cited: 2017 December 27]. Available from: http://woncaeurope.org/content/652influence-socioeconomic-status-incidents-diseases-twodifferent-municipalities-skopje.

6. Williamson I. Otitis media with effusion in children. BMJ Clin Evid. 2011;12(2011):0502.

7. Willems S, De Maesschalck S, Deveugele M, Derese A, De Maeseneer J. Socioeconomic status of the patient and doctorpatient comminication: Does it make a difference? Patient Education and Counseling. 2005;56(2):139-46.

8. Power C, Matthews S. Origins of health in equalities in a national population sample. Lancet. 1997;350(9091):1584-9.

9. Wahid FI, Khan A, Khan IA. Complications of chronic suppurative otitis media: Challenge for a developing country. Kulak Burun Bogaz Ihtis Derg. 2014;24(5):265-70.

10. Zhang Y, Xu M, Zhang J, Zeng L, Wang Y, Zheng QY. Risk factors for chronic and recurrent otitis media-a meta-analysis. PLoSOne. 2014;9(1):e86397.

11. Koch A, Homøe P, Pipper C, Hjuler T, Melbye M. Chronic suppurative otitis media in a birth cohort of children in Greenland: Population based study of incidence and risk factors. Pediatr Infect Dis J. 2011;30(1):25-9.

12. Kim CS, Jung HW, Yoo KY. Prevalence and risk factors of chronic otitis media in Korea: results of a nation-wide survey. Acta Otolaryngol. 1993;113(3):369-75.

13. Pedersen CB, Zachau-Christiansen B. Otitis media in Greenland children: acute, chronic and secretory otitis media in three to eight year olds. J Otolaryngol. 1986;15(6):332-5.

14. McNiel ME, Labbok MH, Abrahams SW. What are the risks associated with formula feeding? Are-analysis and review. Breastfeed Rev. 2010;18(2):25-32.

15. Humaid AH, Ashraf AH, Masood KA, Nuha AH, Saleh AD, Awadh AM. Prevalence and risk factors of Otitis Media with effusion in school children in Qassim Region of SaudiArabia. Int J HealthSci (Qassim). 2014;8(4):325-34. 